\title{
A survey of postnatal contraception in opiate-using women
}

\author{
Chitra Sinha, Kate A Guthrie, Stephen W Lindow
}

\begin{abstract}
Objective To document the contraceptive choices and continuation rates for different contraceptives in a group of pregnant women who use opiates.

Methods A prospective study set in a large city in the north of England that looked at 40 pregnant women who used opiates in the index pregnancy. The study involved reviewing the records from the patients' general practitioners with information on the continuation rates of the chosen method of contraception and any related problems.
\end{abstract}

Results The women given Depo-Provera $\AA(n=14)$ did not continue the method after the first injection. Those given implants $(n=20)$ had a $95 \%$ continuation rate at a mean follow-up of over 11 months.

Conclusions Implants had a good continuation rate when used for postnatal contraception in women who used opiates in pregnancy. Depo-Provera may not be a suitable choice since all the women who chose this contraceptive method failed to continue with it.

Keywords Depo-Provera ${ }^{\odot}$, implants, opiates, postnatal contraception, pregnancy

J Fam Plann Reprod Health Care 2007; 33(1): 31-34

(Accepted 20 March 2006)

\section{Introduction}

There has been minimal work performed and published on the subject of contraceptive use in women who use drugs. Previous work has outlined the perinatal problems associated with this group of women.1,2 In addition, medical problems are frequent and are secondary to lifestyle and habits. Hepatitis, HIV and multiple abscesses are common because of unsterile injecting techniques, and prostitution to finance the addiction may lead to the development of other sexually transmitted infections. Logically, if unplanned pregnancies in a high-risk group can be prevented then this will reduce the overall incidence of adverse pregnancy outcome.

A local survey indicated that all the pregnancies in this group of women were unplanned and no contraception was used before pregnancy (Lindow, personal observation). Safe and effective contraception, which is easily accessible, will help this group of women make appropriate choices about their future fertility.

Contraception has a low priority in opiate-using women and there are a number of possible reasons. Menstrual irregularities are commonly associated with the use of heroin in high doses. Menstruation usually ceases after 1-4 months of heroin use. ${ }^{3}$ It has been shown that $64-73 \%$ of females addicted to heroin will have oligomenorrhoea or amenorrhoea. ${ }^{4}$ The mechanism of action of this menstrual dysfunction is unknown. It is postulated that there is suppression of ovulation either by the direct effects of opiates depressing the pituitary gland or the hypothalamus or effecting a neural block between the pituitary gland and the hypothalamus with a resultant decrease in gonadotrophin output. ${ }^{4}$

Contrary to expectation, the fertility of heroin addicts has been shown to be unaffected. ${ }^{5}$ This might be explained

\footnotetext{
Women and Children's Hospital, Hull Royal Infirmary, Hull, UK

Chitra Sinha, DFFP, MRCOG, Staff Grade in Sexual Health Kate A Guthrie, MFFP, FRCOG, Consultant in Sexual Health Stephen W Lindow, MD, FRCOG, Senior Lecturer in Perinatology
}

Correspondence to: Dr Stephen W Lindow, Women and Children's Hospital, Hull Royal Infirmary, Anlaby Road, Hull HU3 2JZ, UK. E-mail: stephen.lindow@hey.nhs.uk

\section{Key message points}

- Postnatal contraception is an important but neglected issue in the care of women who use opiates in pregnancy.

- Depo-Provera ${ }^{\odot}$ may not be suitable as continuation rates are low.

- Implants had good continuation rates when used for postnatal contraception.

on the basis of the fluctuating amount of heroin received via self-administration ${ }^{6}$ producing an intermittent pituitary suppression.

Conventional wisdom previously held that the motivation for contraception is highest immediately after childbirth, however more recent papers challenge this assumption. ${ }^{7}$ A recent study in Scotland showed that nearly all counselling on postpartum contraception that had occurred on the postnatal wards as part of a routine checklist was a waste of time since the women themselves reported receiving little advice which was of poor quality. 8 These authors argue that mothers are uninterested in contraception in the immediate postpartum and they do not absorb the information given to them as they are preoccupied with the care of the newborn. It has been shown that antenatal counselling for family planning and contraception is a useful strategy. ${ }^{9}$ The antenatal discussion should focus on issues related to postpartum conditions that can affect choice and the timing of various contraceptive methods. ${ }^{10}$

At Hull Maternity Hospital in Hull, UK a multidisciplinary care team is provided for the increasing number of opiate-using mothers booked for antenatal care. This team includes a dedicated midwife, a staff grade doctor, a consultant obstetrician (with a special interest in medical problems in pregnancy) and a paediatrician. All women participate in a discussion on contraception in the antenatal period.

Drug counselling and methadone prescribing is carried out by Specialist Substance Misuse Services (SSMS) or the patient's own general practitioner (GP). This is supplemented by psychiatric and psychological counselling where necessary. 
Sinha et al.

\begin{tabular}{|c|c|c|c|c|c|}
\hline \multirow[t]{2}{*}{ Contraceptive method } & \multicolumn{4}{|c|}{ Category of drug use $(n)$} & \multirow{2}{*}{$\begin{array}{l}\text { Total }(n(\%)) \\
(n=40)\end{array}$} \\
\hline & $\begin{array}{l}\text { Heroin } \\
(n=9)\end{array}$ & $\begin{array}{l}\text { Heroin and methadone } \\
(n=11)\end{array}$ & $\begin{array}{l}\text { Methadone } \\
(n=10)\end{array}$ & $\begin{array}{l}\text { Nil } \\
(n=10)\end{array}$ & \\
\hline OCP & 0 & 1 & 0 & 1 & $2(5)$ \\
\hline Depo-Provera ${ }^{\circledR}$ & 0 & 5 & 5 & 4 & $14(35)$ \\
\hline Norplant ${ }^{\circledR}$ & 7 & 0 & 0 & 3 & $10(25)$ \\
\hline Implanon ${ }^{\circledR}$ & 2 & 4 & 4 & 0 & $10(25)$ \\
\hline IUD & $\overline{0}$ & 0 & 0 & 1 & $1(2.5)$ \\
\hline Sterilisation & 0 & 0 & 0 & 1 & $1(2.5)$ \\
\hline None & 0 & 1 & 1 & 0 & $2(5)$ \\
\hline Contraception total (n (\%)) & $9(100)$ & $10(91)$ & $9(90)$ & $10(100)$ & $38(95)$ \\
\hline
\end{tabular}

IUD, intrauterine device; OCP, oral contraceptive pill.

This survey was undertaken to assess the provision of contraceptive services to opiate-using women in the postnatal period in three ways:

1. To determine the spectrum of use of postpartum contraception.

2. To document the continuation rate when the chosen method was provided.

3. To identify any method of contraception which appears to be suitable.

\section{Methods}

This prospective study of contraception use (January 1998 to May 2000) involved women who were using opiates during their antenatal and postnatal periods who were booked for delivery at Hull Maternity Hospital. The opiates used were heroin, methadone or both used simultaneously. The identification or disclosure of opiate usage was by selfdeclaration to the midwife taking the booking history or by the information provided by referral letter from the woman's GP or other agency.

All the women were asked whether the present pregnancy was planned, and methods of contraception were discussed antenatally and information was given both verbally and in written leaflet form and documented in the case notes. One of the authors (C.S.) obtained consent for the follow-up at the time when contraception was provided to these patients.

All opiate-using women were seen after delivery on the postnatal wards at Hull Maternity Hospital and future contraception was discussed and provided immediately or at a later date as required. Wherever possible, contraception was recommended in the form of DepoProvera ${ }^{\circledR}$ or progestogen implants.

\section{Follow-up}

The women's GPs were contacted in May 2000 to gain information about contraception and any side effects reported to them. One of the authors (C.S.) personally visited the GP's surgery after obtaining an appointment. After reviewing the GP's records, a standardised data form was completed by C.S. and the GP together.

\section{Ethical approval}

Permission from the East Riding of Yorkshire Ethics and Research Committee was obtained for this study.

\section{Results}

During the study period (January 1998 to May 2000) there were 40 opiate-using pregnant women booked for hospital confinement. All of the pregnancies were unplanned and no immediate previous contraception was used. The women's mean age was 23.7 years and mean parity was 2.1 . Only one of the 40 women was married, one woman had previous medical problems and all the women were unemployed.

Most of the pregnant heroin users were injecting heroin except one who was smoking heroin and had never injected. The duration of opiate use varied from 6 months to 6 years. None of the patients included in this study was a confirmed commercial sex worker at the time of the study.

All 40 women were prescribed methadone in the antenatal period. Post-delivery 10 women were taking methadone, nine went back to using heroin and stopped methadone, 11 women were using both heroin and methadone and 10 had stopped opiate use completely.

All 40 babies were admitted to the special care baby unit for observation and none were breastfed.

Fourteen women had Depo-Provera intramuscularly for contraception that was initiated from Days 4 to 21 postpartum (Table1).

Twenty women had implants ( 10 had Norplant ${ }^{\circledR}$ and 10 had Implanon ${ }^{\circledR}$ ) that were inserted from Days 7 to 28 postpartum, and this method was ongoing for a mean of 11.6 and 11.9 months, respectively (Table 2 ).

One woman had a sterilisation performed at 6 weeks postpartum, two were taking the oral contraceptive pill and one woman had an intrauterine device (IUD) fitted at 6 weeks postpartum. Two women did not receive any contraception (Table 2).

Four women complained of irregular bleeding and one woman had her Norplant removed because of weight gain (Table 2).

Table 2 Contraception follow-up in the study group

\begin{tabular}{|c|c|c|c|c|}
\hline \multirow[t]{2}{*}{ Follow-up details } & \multicolumn{4}{|c|}{ Contraceptive method } \\
\hline & $\begin{array}{l}\text { Depo-Provera }{ }^{\circledR} \\
(n=14)\end{array}$ & $\begin{array}{l}\text { Norplant }{ }^{\circledR} \\
(n=10)\end{array}$ & $\begin{array}{l}\text { Implanon }{ }^{\circledR} \\
(n=10)\end{array}$ & $\begin{array}{l}\text { Othera } \\
(n=6)\end{array}$ \\
\hline Postpartum day started (range in days) & $4-21$ & $7-28$ & $7-28$ & $7-42$ days \\
\hline Mean duration of use (months) & 3.5 & 11.6 & 11.9 & 12 \\
\hline Discontinued (n (\%)) & $14(100)$ & $1(10)$ & $0(0)$ & $0(0)$ \\
\hline Reported problems & None & Irregular bleeds (2), weight gain (1) & Irregular bleeds (2) & None \\
\hline Continuation (\%) & 0 & 90 & 100 & 100 \\
\hline
\end{tabular}

aComprising sterilisation (1), oral contraceptive pill (2), IUD (1), no contraception (2). 
Those women who continued using heroin only $(n=9)$ did not keep their follow-up appointment with the GP or any appointment with SSMS or the postnatal clinic.

In summary, 30/40 women continued opiate use in one form or another after delivery. Contraception was given to 95\% of women, however those given Depo-Provera did not attend follow-up and repeat doses of the contraceptive. Continuation rates of contraceptive implants were $90 \%$ and $100 \%$ at a mean of 11.6 and 11.9 months for Norplant and Implanon, respectively.

\section{Discussion}

This study found a high uptake of contraception among opiate-users after delivery. The duration of use was longer if progestogen implants were used and poor if DepoProvera or other methods were used.

A $100 \%$ follow-up is reported in this study as one of the authors (C.S.) personally visited the GPs' surgeries and the two doctors in combination completed the standard data form after consulting the records.

Follow-up at family planning clinics was not included because it is unlikely that these women would contact the clinics as they were already attending their GP's surgery and SSMS for methadone prescriptions. In Hull at the time of the study only two persons were qualified to remove implants (K.A.G. and C.S.) and the implants removed by these two doctors are considered in the Results section. One of the authors (C.S.) also worked at SSMS and therefore was in a position to review contraceptive needs.

The choice of postpartum contraception methods depends on many factors, including the need for a temporary versus a permanent method, the infant-feeding choice and the extent to which consent is given prior to delivery. For maximum protection, non-breastfeeding women should use contraception from the fourth week as many women become sexually active earlier than 6 weeks postpartum - the traditional time for postpartum checkup..$^{11}$ The first ovulation in a non-breastfeeding woman has been observed on average at 45 days. ${ }^{12}$

Heroin crosses into breast milk in sufficient quantities to cause addiction in the infant. A milk:plasma ratio has not been reported. The American Academy of Paediatrics ${ }^{13}$ states that heroin misuse is a contraindication to breastfeeding. Breastfeeding, however, may reduce withdrawal in the neonate and diminish the need for pharmacotherapy in the baby. ${ }^{14}$ The baby of a mother on a stable dose of opiate will simply continue to receive the amount of the drug it received in utero. Finnegan 15 suggested that it might be useful to wean the baby at about 3-6 months because the volume of milk consumed is greater as is the subsequent ingestion of drug.

The choice of postpartum contraception for opiate users apart from the factors mentioned above is also influenced by the continuation of opiate use, risk-taking behaviour and failure to keep appointments with their GP or family planning clinic.

\section{Contraceptive choices}

There should be facilities for opiate-using women where contraception can be discussed and provided at places where the young women go to collect their methadone prescription. Appointments are not generally kept if made with other doctors or agencies. When contraception is discussed, emphasis should be placed on long-term contraception in the form of implants, Depo-Provera, IUDs and the levonorgestrel-releasing intrauterine system (IUS).

Postpartum contraception in the form of implants (which need minimum medical input after insertion) was well accepted, specifically in the heroin- and methadoneusing women.

\section{Implants}

Contraceptive implants have been the subject of intensive research for the past 25 years. The concept is attractive to users and clinicians alike as the implants provide longlasting, highly effective and reversible contraception requiring no further actions by the users. Consequently, in studies as in clinical practice, user failure rates are similar to the method failure rates. Such implants closely approach fulfilling the criteria of an ideal contraceptive for many women.

Contraceptive implants are well tolerated, with continuation rates and user satisfaction levels high among users who have undergone pre-insertion counselling. This is despite users reporting a significant incidence of side effects, and can probably be justified by individual women who must weigh up the advantages of such a method against nuisance side effects. This was confirmed by the continuation of this form of contraception by the opiateusing women in this study. Continuation rates for Implanon and Norplant are similar; about $80 \%$ of users continue with this method for at least 2 years. ${ }^{16}$

Insertion and removal of contraceptive implants constitute minor surgical procedures with risks such as infection and bleeding similar to any minor operation.

\section{Depo-Provera}

Depo-Provera comprises an injection of $150 \mathrm{mg}$ depot medroxyprogesterone acetate given intramuscularly every 3 months. The plasma level of progestogen that results from the injectable formulation is higher than from oral or implanted methods. When administered immediately postpartum Depo-Provera does not pose a thrombogenic threat, however concern has been raised about progestogen injections given prematurely to breastfeeding women. The natural precipitous fall in progesterone within the first 1-3 days in the postpartum period may be the trigger for lactogenesis. When exogenous progestogens are administered prior to the natural postpartum decline in the progesterone level problems may arise with the establishment of breastfeeding. This hypothesis has not been examined nor has the extent to which breastfeeding problems are associated with the early administration of progestogens. The general agreement is to postpone the use of the progestogen injection method for 6 weeks during breastfeeding to avoid this problem.

Fewer side effects were reported in the form of irregular bleeding or weight gain compared to Norplant or Implanon use. Depo-Provera continuation rates were poor, however, and the average duration of use was only 3.5 months. Clearly this form of contraception does not provide significant cover for this group of women because it is important to remember to have the injection every 12 weeks. In women with a chaotic lifestyle this may not be possible on a consistent basis.

\section{IUD}

If a woman chooses to have an IUD fitted for contraception there is always the additional risk of pelvic infection (i.e. pelvic inflammatory disease, PID). If a woman is working as a commercial sex worker this risk is increased, therefore she should understand the risk and be advised that additional barrier contraception may reduce her chances of PID.

It now seems clear that the IUD offers little protection against PID, and so IUD use by high-risk women who are 
not in a monogamous relationship is not recommended. It is suggested that sexual behaviour is the most important risk factor for PID in copper-releasing IUDs. ${ }^{17}$

\section{Levonorgestrel IUS}

The IUS has been suggested to offer protection against PID because of its progestogenic effect on cervical mucus. The European Multicentre Study showed a lower risk of PID in IUS users compared with the copper-releasing IUDs. ${ }^{18}$

\section{Conclusions}

Unplanned pregnancy is common in opiate users because their menstrual cycle is irregular or amenorrhoeic and no contraception may be used as it is not thought to be needed by the women concerned.

Classically, pregnant heroin users have been reported to be late bookers for antenatal care, present with untreated medical diseases and have a high incidence of obstetric complications. If contraceptive advice is available at a place that is easily accessible to this subgroup of the population it will reduce unplanned pregnancy and associated complications.

Long-term contraceptive methods such as implants and IUDs are more suitable for drug-using women as they require minimal medical supervision. This study has shown good continuation rates for Norplant $(90 \%)$ and Implanon $(100 \%)$ but not Depo-Provera. It would appear that the long-term implants might play a dominant role in contraceptive care for this group of women.

Statements on funding and competing interests

Funding None identified.

Competing interests None identified.

References

1 Sinha C, Ohadike P, Carrick P, Pairaudeau P, Armstrong D, Lindow SW. Neonatal outcome following opiate use in late pregnancy. Int J Obstet Gynaecol 2001; 74: 241-246.

2 Jha RR, Carrick P, Pairadeau P, Armstrong D, Lindow SW.
Maternal opiate use: pregnancy outcome in patients managed by a multidisciplinary approach. J Obstet Gynaecol 1997; 17: 331-334.

3 Kaman A, Stroang R. Obstetric and gynaecological aspects of heroin addiction. Am J Obstet Gynecol 1962; 83: 252.

4 Gaulden E, Littlefield D, Putoff B, Sievert A. Menstrual abnormalities associated with heroin addiction. Am J Obstet Gynecol 1064; 90: 155-157.

5 Fraser A, Cavanagh S. Pregnancy and drug addiction longterm consequences. J Roy Soc Med 1991; 84: 530-532.

6 Stoffers A. A gynaecological study of drug addicts. Am J Obstet Gynecol 1968; 101: 779.

7 Winikoff B, Mensch B. Rethinking postpartum family planning. Stud Fam Plann 1991; 22: 294-307.

8 Glasier AF, Logan J, McClew TJ. Who gives advice about postpartum contraception? Contraception 1996; 53: 217-220.

9 Walton SM, Gregory H, Crosbie-Ross G. Family planning counselling in antenatal clinics. Br J Fam Plann 1987; 13: 136-139.

10 Kennedy KI. Post-partum contraception (Review). Baillieres Clin Obstet Gynaecol 1996; 10: 25-41.

11 Maybray CR. Postpartum examination; a re-evaluation. South Med J 1979; 72: 1433-1435.

12 Gray RH, Campbell OM, Zacur HA, Labbock MH, MacRae SL. Postpartum return of ovarian activity in nonbreastfeeding women monitored by urinary assays. J Clin Endocrinol Metab 1987; 64: 645-650.

13 American Academy of Paediatrics, Committee on Drugs. Effect of maternal opiate abuse on the newborn. Fed Proc 1994; 44: 2314-2317.

14 Hepburn M. Drug misuse in pregnancy. Br J Hosp Med 1993; 49: 51-55.

15 Finnegan LP. Treatment issues for opioid-dependent women during the perinatal period (Review). J Psychoactive Drugs 1991; 23: 191-201.

16 Edwards JE, Moore A. Implanon. A review of clinical studies. $\mathrm{Br}$ J Fam Plann 1999; 24(4 Suppl.): 3-16.

17 Farley TM, Rosenberg MJ, Rowe P, Chen JH, Meirik O. Intrauterine device and pelvic inflammatory disease, an international perspective. Lancet 1992; 339: 785-788.

18 Toivonen J, Luukkainen T, Allonen $\mathrm{H}$. The effect of intrauterine release of levonorgestrel on pelvic infection: three years' comparative study of levonorgestrel- and copper-releasing intrauterine contraceptive devices. Lancet 1991; 77: 221-224.

\section{FACULTY AWARDS}

The Faculty of Family Planning and Reproductive Health Care has available a number of annual awards for which applications are invited from Faculty members and non-members as listed below. Details of the individual awards, together with an application form and/or guidelines on how to apply and any eligibility criteria, may be found on the Faculty website at www.ffprhc.org.uk.

\section{Margaret Jackson Prize Essay}

Award: Three prizes awarded annually for the best essays on a topic related to contraceptive and sexual health care. The first prize is $£ 300$, with $£ 100$ each for the two runners-up.

Eligibility: Individuals (undergraduate medical students)

\section{Closing date: 24 March annually}

\section{The David Bromham Annual Memorial Award}

Award: Prize awarded for a piece of work which through inspiration, innovation or energy has furthered the practice of family planning and reproductive health care in any way and any setting.
Eligibility: Individuals (Faculty members) or teams
Closing date: 7 April annually

\section{International Travelling Scholarship of the Faculty}

Award: Scholarship up to the value of $£ 2000$ to fund travel abroad to visit international colleagues, services, research or educational establishments to learn about some aspect of family planning or reproductive health care.

Eligibility: Individuals (Faculty members)

Closing date: 7 April annually

The 4-0-8 Sheffield Fund

Award: Approximately $£ 1000$ will be allocated every 3 months, either as a single award or divided between the successful applicants, for the purpose of funding training for health care professionals who have limited funding for attending training meetings.

Eligibility: Individuals (Faculty members/non-members) Closing date: See website for details 